\title{
LEI MARIA DA PENHA: ANÁLISE A PARTIR DA VITIMOLOGIA CRÍTICA DE ORIENTAÇÃO FEMINISTA BRASILEIRA ${ }^{1}$
}

MARIA DA PENHA LAW: ANALYSIS FROM THE CRITICAL VITIMOLOGY OF BRAZILIAN FEMINIST ORIENTATION

Maria Fernanda FALCAI ${ }^{2}$

Gustavo de Carvalho MARIN ${ }^{3}$

ISSUE DOI: $10.21207 / 2675-0104.2018 .780$

\begin{abstract}
RESUMO
O presente trabalho foi desenvolvido com o objetivo de analisar a Lei Maria da Penha (LMP), Lei ${ }^{\circ}$ 11.340/2006, a partir da vitimologia crítica de orientação feminista. Foram realizados também estudos sobre o movimento feminista, suas peculiaridades, e o impacto que teve para a criação de uma lei que defenda os direitos humanos das mulheres. Neste trabalho foi desenvolvido em ordem cronológica todo o processo até a promulgação da LMP e uma comparação de quando era aplicada aos casos de violência doméstica e familiar, a Lei $\mathrm{n}^{\circ}$ 9.099/95, e o que foi alterado depois que foi retirada sua competência. Conclui-se que A Lei Maria da Penha possui grande representatividade e importância no mundo
\end{abstract}

\footnotetext{
${ }^{1} \mathrm{O}$ presente artigo sintetiza a monografia de conclusão da pesquisa, realizada para o Programa Interno de Bolsas de Iniciação Científica (PIBIC 2017-2018) da Faculdade de Direito de Franca (FDF), Franca/SP.

${ }^{2}$ Discente da Faculdade de Direito de Franca (FDF), Franca/SP. Bolsista do Programa Interno de Iniciação Científica (PIBIC 2017-2018).

${ }^{3}$ Professor Doutor da Universidade do Estado de Minas Gerais (UEMG), no curso de Direito do campus Ituitaba-MG. Doutor e Mestre em Direito pela Universidade de São Paulo (Faculdade de Direito-FD/USP). Especialista em Vitimologia pela Universidade de Sevilha (Espanha). Graduação em Direito pela Universidade de São Paulo (Faculdade de Direito de Ribeirão Preto-FDRP/USP, Bolsista CNPq). Foi pesquisador visitante na Universidade de Sevilha (Espanha) e no Instituto Max Planck para Direito Penal Estrangeiro e Internacional (Freiburg, Alemanha). Coordenador Adjunto do Departamento Mesas de Estudos e Debates e do Departamento de Monografias do Instituto Brasileiro de Ciências Criminais (IBCCRIM).
} 
jurídico, promoveu um alcance maior para a igualdade, suprindo a dívida que o Estado possuía com as mulheres, depois de anos de tratamentos desiguais, em que o homem era visto como detentor de todo o poder, e a mulher como incapaz, submissa a ele. Porém, em relação à prevenção ainda há muito a ser debatido e colocado em prática para a real eficácia da Lei.

Palavras-chave: Lei Maria da Penha; ideologia patriarcal; feminismo; direito penal;

\section{ABSTRACT}

The present paper was developed with the purpose of analyzing the Maria da Penha Law (MPL), Law $n^{\circ} 11.340 / 2006$, based on critical feminist orientation victimology. Studies were also carried out on the feminist movement, its peculiarities, and the impact it had on the creation of a law to defend women's human rights. In this work, the entire process was developed chronologically until the enactment of the MPL and a comparison of when it was applied to cases of domestic and family violence, Law 9,099 /95, and what was changed after its competence was withdrawn. It is concluded that The Law Maria da Penha has great representation and importance in the legal world, promoted a greater reach for equality, supplying the debt that the State had with women, after years of unequal treatment, in which the man was seen as the possessor of all power, and the woman as incapable, submissive to him. However, regarding prevention there is still much to be debated and put into practice for the real effectiveness of the Law.

Keywords: Lei Maria da Penha; patriarchal ideology; feminism; criminal law;

\section{INTRODUÇÃO}

Historicamente, a mulher sofreu e ainda sofre vários tipos de violências por razões de gênero, sejam elas físicas, psicológicas ou morais. No Brasil, ações de movimentos feministas e a dimensão pública do debate culminaram na Lei Maria da Penha ("LMP" - Lei no 11.340/2006), orientada à proteção das mulheres vitimizadas.

Discute-se na pesquisa o papel do Direito Penal neste cenário, diante da constatação de Alessandro Baratta, segundo quem o "controle penal age de forma reativa e não preventiva". A pesquisa tem como objeto a análise da LMP a partir de vertentes feministas da vitimologia crítica.

Propõem-se os seguintes questionamentos, dentre outros: $\mathrm{O}$ controle feito pelo Direito Penal é eficaz? Caso a mulher não queira prosseguir com a persecução do agressor, quais são as consequências? São aplicadas as medidas despenalizadoras? Quais seriam as alternativas para mitigar ou encerrar o ciclo de violências de gênero contra mulheres?

$\mathrm{O}$ artigo utiliza o método dedutivo; ou seja, parte de uma premissa geral para chegar a conclusões mais restritas. Para tanto, vale-se da revisão sistemática de bibliografia relativa ao assunto, além de analisar incidentalmente a jurisprudência sobre a LMP.

No primeiro capítulo será abordada a realidade da sociedade patriarcal brasileira, todo seu histórico, bem como a condição de ser mulher 
no Brasil. Também será conceituado os termos: machismo, patriarcado e misógino.

O segundo capítulo contará todo o percurso do movimento feminista no brasil, e sua importância. Serão destacados os relevantes pontos que levaram à reinvindicação de uma lei que tratasse sobre violência contra a mulher.

O terceiro capítulo conceituará violência de gênero, suas características e peculiaridades e, também a vitimologia que é a forma escolhida de estudo para analisar a lei.

Todos esses capítulos e detalhes se contextualizarão com a abordagem feita no quarto capítulo, em que será feita a análise da lei, no que tange à sua efetividade, comparando-a como era antes de sua realização, os avanços, as problemáticas e críticas.

\section{HISTÓRICO SOBRE A SOCIEDADE PATRIARCAL, MACHISMO, MISOGINIA, A CONDIÇÃO DE SER MULHER NO BRASIL E A VIOLÊNCIA DE GÊNERO}

Para analisar o patriarcado e estabelecer com clareza sua definição, e a de machismo, é importante observar o conteúdo histórico até chegar aos dias atuais.

$\mathrm{Na}$ Roma antiga, o poder concentrava-se todo no pai, o patriarca da família. Esse poder abrangia a mulher, os filhos, os escravos e os vassalos e prevalecia até sobre o poder do Estado.

Vale ressaltar que o patriarcado não significa o poder do pai lato sensu, mas o poder masculino, centrado na figura do homem.

$\mathrm{Na}$ Grécia antiga também é possível observar essa visão de inferioridade sob a mulher, esta ocupava a posição de que apenas lhe servia os trabalhos manuais, menosprezados pelos homens livres. Em Atenas, o primeiro requisito para ser livre era ser homem, ou seja, a mulher não era livre, portanto, propriedade do homem livre -ateniense, não estrangeiro e não escravo.

Durante toda nossa vida temos contatos com pensadores e filósofos, muitas vezes os estudamos, mas quando vamos analisar a fundo, nos deparamos com o conteúdo machista e misógino que propagavam. Um exemplo disso é a afirmação de Platão, que contextualiza o que foi dito 
acima: "Se a natureza não tivesse criado as mulheres e os escravos teria dado ao tear a propriedade de fiar sozinho".

A característica principal da sociedade patriarcal é o homem ser o detentor de todo o poder, sendo desvalorizado o feminino, ou seja, a mulher em estado de submissão em relação a ele.

\begin{abstract}
“Alda Facio (1999), al definir al patriarcado como la ideología y las estructuras institucionales que mantienen la opre-sión de las mujeres, nos habilita a pensar las instituciones como la familia y la justicia, entre otras, como aquellas que promueven el consenso en torno a un orden social, económico, cultural, religioso y político, que determinan que el grupo, casta o clase compuesto por mujeres, siempre esté subordinado al grupo, casta o clase compuesto por hombres." ${ }^{4}$
\end{abstract}

É possível identificar a inferiorização da mulher em diferentes épocas da história do mundo, além das já mencionadas, não poderia deixar de citar a Idade Média. Um dos marcos dessa época é a Inquisição, em que houve perseguição aos hebreus, que é muito estudado até hoje, mas o que é pouco falado é sobre "a caçadas às bruxas" que ocorreu durante a Idade Média, tanto na Europa quanto nas Américas.

Essa caçada era caracterizada pela perseguição às mulheres, as quais eram condenadas e queimadas. Nessa perseguição ás ditas "feiticeiras" existe um elemento claro de luta pela manutenção de uma posição de poder por parte do homem: a mulher, tida como bruxa supostamente possuiria conhecimentos que lhe conferiam espaços de atuação que escapavam do domínio masculino5, e por isso houve essa perseguição, para manter o patriarcado, o poder do homem, a submissão da mulher.

O sentido de patriarcado e sociedade patriarcal mencionado acima remete a História Antiga e Idade Média, mas, algumas semelhanças foram herdadas e podem ser observadas na sociedade atual em que vivemos e transformou-se em machismo, ou ainda, pode-se falar em comportamento misógino.

"A MULHER? É muito simples, dizem os amadores de fórmulas simples: é uma matriz, um ovário; é uma fêmea, e esta palavra basta para defini-la. Na boca do homem o epíteto "fêmea" soa como um insulto; no entanto, ele não se envergonha de sua animalidade,

\footnotetext{
${ }^{4}$ GONZÁLEZ, Manuela Graciela. Violencia contras las mujeres, discurso y justicia; compilado por Manuela Graciela González. - 1a ed . - La Plata : EDULP, 2016. p. 51.

5 ALVES, Branca Moreira; PITANGUY, Jacqueline. O que é FEMINISMO. São Paulo: Abril Brasiliense, 1985. P.21.
} 
sente-se, ao contrário, orgulhoso se dele dizem: "É um macho!" O
termo "fêmea" é pejorativo, não porque enraíze a mulher na
Natureza, mas porque a confina no seu sexo. E se esse sexo parece
ao homem desprezível e inimigo, mesmo nos bichos inocentes, é
evidentemente por causa da inquieta hostilidade que a mulher
suscita no homem; entretanto, ele quer encontrar na biologia uma
justificação desse sentimento." (Beauvoir, 1970, p.25).

Essa herança gerou desigualdade para as mulheres em relação ao homem, e hoje é possível verificar a luta para equiparar os direitos.

Em relação aos direitos das mulheres quando comparado ao dos homens, precisa ser falado em equidade entre estes, antes de igualdade.

É falado em equidade, pelo fato de que o homem tem anos de direitos à frente da mulher. Portanto, para alcançar a igualdade material é preciso equiparar antes, ir além da igualdade formal ou do princípio da igualdade perante a lei.

O processo discriminatório que ocorre desde a antiguidade até os dias atuais, não desaparece somente com leis que dizem ambos os sexos serem iguais, é necessário ir além.

Compreendem-se por machismo atitudes, pensamentos $\mathrm{e}$ costumes que fazem com que os homens acreditem serem superiores às mulheres. Todos esses fatores são caracterizam-se como discriminatórios.

Alguns exemplos de comportamentos machistas que podem ser observados ainda hoje no Brasil, são relacionados às tarefas domésticas, acreditam ser de absoluta responsabilidade da mulher os cuidados com o lar e os filhos.

Outros exemplos são o da mulher receber salário desigual ao do homem, mesmo ocupando cargos iguais e, no caso de mulheres que sofreram algum tipo de violência sexual, utilizam falas misóginas para tentar justificar ou culpabilizar a vítima, havendo sua revitimização, a violência doméstica, que pode ir desde uma violência psicológica até sua forma mais grave, o Feminicídio.

A ideologia patriarcal está até hoje extremamente enraizada na sociedade, nas instituições e mesmo no poder judiciário: até a década de 1970, a tese de legítima defesa da honra era aceita nos tribunais para inocentar maridos que assassinavam seu cônjuge. A Constituição de 1988 expressamente determinou a igualdade entre os homens e as mulheres, mas foi apenas em 1995, com a Lei ${ }^{\circ}$ 9.520, que revogou o artigo 35 do Código de Processo Penal, que estabelecia que a mulher casada não poderia exercer 
o direito de queixa sem a autorização do marido, salvo quando fosse contra ele, ou que esta estivesse separada. ${ }^{6}$

Pode-se conceituar violência contra a mulher de várias maneiras, dentre elas, encontra-se a definição jurídica de Sonia Rovinski, que foi dita na Conferência de Beijing:

\footnotetext{
"É qualquer ato de violência que tem por base o gênero e que resulta ou pode resultar em dano ou sofrimento de natureza física, sexual ou psicológica, incluindo ameaças, a coerção ou a privação arbitrária da liberdade, quer se produzam na vida pública ou privada." (ROVINSKI, 2004, p. 6)
}

As formas de violência contra a mulher são várias, dentre elas e também descriminadas na Lei Maria da Penha (Lei $\mathrm{n}^{\circ}$ 11.340/2006) no Artigo $7^{\circ}$ : física, psicológica, sexual, moral e patrimonial. No entando, trata-se de um rol apenas exemplificativo, dando margem para, caso surge novos tipos de violência, a lei conseguir abarcar.

\section{FEMINISMO, SUA IMPORTÂNCIA ATÉ A CHEGADA DA LEI MARIA DA PENHA E A CRIAÇÃO DE UMA LEI PARA COMBATER A VIOLÊNCIA CONTRA A MULHER}

Falar sobre Feminismo e o definir, é complexo. Mas algo precisa ser deixado claro: Feminismo não é o contrário de machismo. Este movimento surge em um dado momento da história em que as mulheres resolvem romper com o silêncio e denunciar a opressão.

O feminismo busca repensar e recriar a identidade de sexo sob uma ótica em que o indivíduo não tenha que se adaptar a modelos hierarquizados, e onde as qualidades "femininas" ou "masculinas" sejam atributos do ser humano em sua globalidade, que as diferenças entre os sexos não se traduzem em relação de poder que interferem em várias dimensões, como na participação política, no trabalho, na esfera familiar, entre outras. $^{7}$

Uma das conquistas das mulheres, que teve grande visibilidade, foi a do sufrágio universal. Foi um movimento feminista que ocorreu no mundo todo e no Brasil ele foi tardio, comparado aos outros países, tendo

\footnotetext{
${ }^{6}$ IPEA - TD - Avaliando a Efetividade da Lei Maria da Penha. 2015. P.9.

7 ALVES, Branca Moreira; PITANGUY, Jacqueline. O que é FEMINISMO. São Paulo: Abril Brasiliense, 1985. P.9-10
} 
início em 1910 quando Deolinda Daltro fundou no Rio de Jan eiro o Partido Republicano Feminino, com a finalidade de ressuscitar o debate sobre o voto feminino que foi iniciado na Constituinte de 1891.

Alguns anos depois surgiu a Liga pela Emancipação Intelectual da Mulher, em 1919 por Bertha Lutz. Neste movimento utilizaram da pressão sobre os membros do Congresso, e assim ganharam visibilidade, força, inclusive jurídica.

Nesse momento da reivindicação das mulheres pelo voto, 10 Estados do país já haviam incluído artigo em suas Constituições Estaduais conferindo o sufrágio, quando em 1932, Getúlio Vargas, através de um decreto-lei promulgou o direito das mulheres votarem.

A partir disso, as mulheres conquistaram o direito de poder frequentar os ambientes escolares e de trabalho. No entanto, anos depois, surgiram questionamentos mais profundos sobre a questão da mulher, denunciando uma diferenciação entre o homem e a mulher em todos os âmbitos.

Nesta fase, surgiu Simone de Beauvoir, e uma de suas constatações ficou muito conhecida: "Não se nasce mulher, torna-se mulher". Ou seja, o ser "homem" e ser "mulher" foi algo culturalmente criado e reproduzido pela sociedade.

Portanto, a luta das mulheres vai muito além das ideias liberais, abrange a dupla jornada da mulher -quando a mulher além de ser inserida no mercado de trabalho, ao chegar em casa tem que desempenhar, sozinha, o papel que organiza a casa-, a hierarquização no ambiente familiar, em que o homem se porta como superior em relação à mulher.

O movimento feminista no Brasil durante a década de 80 , após a redemocratização começou a reivindicar do Estado atitudes de combate à violência doméstica, dentre estas atitudes encontrava-se o pedido de garantir o direito, ou seja, que perante a justiça os direitos humanos das mulheres fossem garantidos.

Neste contexto foi criado o Conselho Nacional dos Direitos das Mulheres, era discutido a violência doméstica e familiar e a necessidade de se implantar políticas publicar para a combater.

No Brasil, durante o ano de 1995 foi aprovada a Lei $n^{\circ}$ 9.099, que foram instituídos os Juizados Especiais Criminais (JECrims), e nesta pesquisa será apenas observada suas características no que tange aos direitos das mulheres, no caso, a violência doméstica e familiar, pois a Lei é abrangente e não era exclusiva para esses casos. 
A Lei $n^{\circ}$ 9.099/95 tratava esse tipo de violência como infração de menor potencial ofensivo, ou seja, enquanto havia pelo mundo o reconhecimento como uma violação dos direitos humanos das mulheres, o Brasil não acatou os pedidos de criação de políticas públicas para tentar reverter a situação.

Essa lei foi criada sob o molde do senso comum masculino, o patriarcado, e não foi feita para combater a violência contra as mulheres. Há autores que dizem que a lei foi criada para resolver crimes eventuais e não habituais. (Campos 2016)

Em meio a todo esse movimento para criar uma forma efetiva de combater a violência contra a mulher, o caso de Maria da Penha Fernandes ganhou repercussão, o ex-marido cometeu duas tentativas de homicídio contra ela: a primeira atirou em suas costas enquanto dormia, esta tentativa a deixou paraplégica, a segunda foi tentando eletrocutá-la.

Estes episódios tiveram início em 1983, mas foi só em 1996 que o agressor foi considerado culpado, este recorreu e o Poder Judiciário brasileiro ficou inerte nesta situação, não oferecendo nenhuma decisão final sobre o caso.

No ano de 1998 o caso de Maria da Penha foi denunciado à Corte Interamericana de Direitos Humanos da Organização dos Estados Americanos (OEA) e, em 2001, o Brasil foi condenado pela mesma por negligência e omissão e foi recomendado ao Estado brasileiro que prosseguisse e intensificasse o processo de reforma que evite a tolerância estatal e o tratamento discriminatório no que diz respeito à violência doméstica contra mulheres no Brasil, além disso foi dito para adotar medidas de capacitação e sensibilização dos funcionários judiciais e policiais especializados para que compreendam a importância de não tolerar a violência doméstica; simplificar os procedimentos judiciais penais para que pudesse ser reduzido o tempo processual, sem afetar os direitos e garantias do devido processo (OEA, 2014).

Em 7 (sete) de agosto de 2006 foi sancionada a Lei $n^{\circ}$ 11.340/2006, que tem nome de Lei Maria da Penha em homenagem ao caso de Maria da Penha Fernandes, simbolizando todas as mulheres vítimas dessa violência, concebida para proteger a mulher em situação de vulnerabilidade em uma relação doméstica, familiar ou íntima. 
A vitimologia, que foi adotada como meio de estudo para o aprofundamento da pesquisa, é um ramo da criminologia, surgiu após a segunda guerra mundial, na década de quarenta e tem como fundador, Benjamin Mendelson.

Primeiramente, o objeto de estudo da vitimologia era o genocídio, caracterizando a macrovitimização. Logo após, o enfoque foi para a área da microvitimização que busca estudar as vítimas que casos mais específicos.

Alvino Augusto Sá define vitimização como "um processo complexo, pelo qual alguém se torna, ou é eleito a tornar-se, um objetoalvo da violência por parte de outrem".

A vitimologia é importante para reconhecer a vítima como nada mais do que pessoa, humana, que possui direitos fundamentais, e seus direitos humanos devem ser preservados e garantidos. Por direitos humanos compreendem-se aqueles direitos básicos, inerentes à pessoa humana, que todos deveriam possuir e usufruir. Portanto, a vitimologia visa, além do estudo da vítima, a garantia dos direitos desta, com o crime seus direitos já foram violados, mas com esse campo de estudo pretendese fazer com que não haja, novamente, mais uma violação de direitos.

Mas qual o motivo de ser denominado em que ramo da vitimologia se enquadra?

A vitimologia crítica de orientação feminista é um ramo da vitimologia que visa a situação das mulheres como vítimas de crimes, e na maioria das vezes crimes que são contra o gênero, como no caso da pesquisa em questão, a violência doméstica.

Seguindo o contexto, o movimento feminista, chegou à conclusão que não era pelos fatos pessoais que tornava uma mulher vítima de violência doméstica, e sim, seu status de subordinação determinado por uma sociedade machista, misógina e ainda patriarcal, ou seja, uma violência baseada no gênero, a qual será estudada na pesquisa nos próximos tópicos.

As feministas, portanto, foram mais enfáticas e incisivas, defendendo que a não intervenção do Direito Penal na esfera privada gerava efeitos danosos, ainda mais prejudiciais do que sua não intervenção, gerando uma sensação de era a violência contra a mulher era aceita, caracterizando uma situação de descriminação, como normal.

E partindo desse pressuposto é que chegaram à conclusão da necessidade de fazer leis voltadas para as mulheres, para as violências que sofrem pelo gênero, ou seja, pelo simples fato de ser mulher, como foi o 
caso da Lei $\mathrm{n}^{\mathrm{o}} 11.340 / 2006^{8}$ e mais tarde a Lei do Feminicídio (Lei ${ }^{\circ}$ $13.104 / 2015)^{9}$.

A falta de efetividade da lei penal fere o princípio da proteção de bens jurídicos, por isso a necessidade de construir ramos voltados aos estudos do direito em relação à violência contra a mulher.

Para entrar a fundo na questão sobre violência de gênero, é preciso compreender o que de fato é gênero e suas construções perante a sociedade. Depois de realizado esse aspecto introdutório será facilitado à compreensão do conceito de violência de gênero, seus aspectos e o quanto está ligada à violência doméstica contra a mulher.

Neste aspecto, pode-se observar que o gênero não se restringe no critério biológico (sexo), vai além, baseando-se em estruturas sociais e culturais, entre homens e mulheres, ao longo de toda a história. E essa distinção gera uma hierarquia de poder e submissão, o que acarreta na desigualdade. Portanto, há uma diferenciação entre sexo (biológico) e gênero (baseado em estruturas sociais).

"O conceito de gênero se situa na esfera social, diferente do conceito de sexo, posicionado no plano biológico" (SAFFIOTI; ALMEIDA 1995, p. 183).

Ao falar de gênero é preciso citar a ideologia de gênero, que é o comportamento socialmente aceito e visto como correto imposto à sociedade, formam a personalidade das pessoas, seus pré-conceitos, tornam negativas e vistas como erradas qualquer atitude além do ensinado como o certo, que geram uma construção social, ou seja, algo que é visto como normal pela sociedade e reproduzida durante gerações, visto como "normal" e o que não se encaixa dentro desse padrão é mal visto pela sociedade e alvo de discriminação.

Atualmente essa visão vem sendo modificada, iniciativa aderida por uma parte da população, que visa além daquilo que a sociedade impõe ao ponto de querer desconstruir conceitos misóginos, patriarcais e machistas que disseminavam sobre as mulheres, como o de que devem ser submissas aos homens ou o ditado que mostra bastante a sociedade misógina que vivemos e a relação que tem com a violência doméstica: "em briga de marido e mulher, ninguém mete a colher".

\footnotetext{
${ }^{8}$ Que ficou conhecida popularmente como Lei Maria da Penha (LMP), será abordada detalhadamente adiante nesta pesquisa.

${ }^{9}$ Essa lei versa sobre o homicídio com base no gênero (pelo simples fato de ser mulher).
} 
Para conceituar violência de gênero, vale a pena ressaltar a definição feita na Convenção Interamericana para Prevenir, Punir e Erradicar a Violência contra a Mulher - Convenção de Belém do Pará:

Ofensa à dignidade humana e manifestação das relações de poder historicamente desiguais entre mulheres e homens.

No que tange à violência doméstica há uma explícita questão de gênero, tornando-se então interligada a violência baseada no gênero com esta. O laço afetivo e a proximidade entre a mulher, vítima, e o homem, agressor (relação doméstica, familiar ou íntima de afeto), a torna ainda mais vulnerável a essa submissão e desigualdade.

Conclui-se que a violência de gênero é uma das consequências e heranças da sociedade patriarcal que vem desde a antiguidade, deixando grandes resquícios no mundo atual.

\section{ANÁLISE DA LEI MARIA DA PENHA SOB A PERSPECTIVA DA VITIMOLOGIA CRÍTICA DE ORIENTAÇÃO FEMINISTA}

A escolha da vitimologia como forma de análise da Lei Maria da Penha (LMP), em específico a vitimologia crítica de orientação feminista, deu-se pelo fato de que a mulher, ainda hoje, mesmo com todo o avanço da sociedade, ainda é vítima de uma hierarquização baseada no sexo, em que é disseminada a ideia de o homem ser detentor do poder, proferindo situações de discriminação, opressão e submissão.

A vitimologia crítica, especialmente de orientação feminista, possui promissora capacidade de rendimento para uma análise críticoreflexiva da LMP e dos distintos processos de vitimização por ela abrangidos.

Como já visto nos capítulos acima, a vitimologia é um ramo da criminologia que visa o estudo das vítimas e por consequência os processos de vitimização -ou revitimização. 
A vítima ao sofrer a violência ${ }^{10}$ dentro de seu ambiente familiar, ou com a pessoa com quem se relaciona ${ }^{11}$, se depara com a primeira vitimização, pelo laço ou envolvimento emocional e afetivo é difícil para tomar a iniciativa de denunciar e tomar as devidas providências.

Quando a vítima toma coragem e vai à delegacia ${ }^{12}$ para denunciar, sofre outra fase de vitimização, então se tem a revitimização. Isso ocorre devido à falta de preparo e especialização para atender mulheres vítimas de violência doméstica ou familiar. Ao ir denunciar, a vítima ainda tem um envolvimento com o seu agressor, e aqueles que a atendem não tem o comprometimento, respeito e imparcialidade quando a vítima se mostra resistente em denunciar.

O sistema jurídico também ocasiona mais um processo de vitimização, uma vez que contém todo um histórico de colocar a mulher em situação de submissão em leis e o homem com o poder, nesta questão o direito vem aos poucos tentando suprir a desigualdade que promoveu, e a Lei Maria da Penha é um exemplo disso, depois de muita movimentação por parte das mulheres e de o Brasil ter sido condenado por omissão, em relação à violência doméstica e familiar, pela $\mathrm{OEA}^{13}$. O mundo jurídico em todos os seus aspectos é predominantemente masculino, por isso a construção do pensamento jurídico se formou e desenvolveu com aspectos desiguais, entre os homens e mulheres, e discriminatórios.

Sobre a revitimização ou sobrevitimização, observa BARROS (2008, p.77):

\begin{abstract}
"É importante ressaltar que a atuação da denominada "polícia investigativa" pode causar possível sobrevitimização, como a decorrente da primeira fase acima analisada, em virtude da falta de preparo das autoridades em lidar com a vítima, que já se encontra fragilizada com a situação vitimizadora, ou, mesmo, da própria estrutura do inquérito e da polícia, assim como das questões estruturais que se denotam da contingência brasileira".
\end{abstract}

A mulher ao se deparar com todos esses processos vitimizatórios, recua e se intimida, pois não encontra o apoio social e respaldo jurídico

\footnotetext{
${ }^{10} \mathrm{O}$ rol exemplificativo sobre violência exposto no artigo $7^{\circ}$ da Lei Maria da Penha (Lei 11.340/2006) e já mencionado na pesquisa.

${ }^{11}$ De acordo com decisão proferida pela terceira turma do STJ, a LMP pode ser aplicada nas relações de namoro. No entanto, deve ser observado o caso de cada processo e precisa ter nexo causal entre o ato delituoso e a relação íntima entre vítima e autor.

${ }^{12}$ A Delegacia da Mulher (DDM)

${ }^{13}$ Organização dos Estados Americanos
} 
necessário para dizer que ela está agindo certo, que a culpa de sofrer violência não é dela.

\section{OS AVANÇOS QUE A LEI PROPORCIONOU E AS} PROBLEMÁTICAS E CRÍTICAS QUE GEROU

O primeiro avanço, e significativo, que deve ser citado é o afastamento da competência da Lei 9.099/95, por consequência, a violência doméstica deixou de ser considerava infração de menor potencial ofensivo. Portanto, afastou-se a possibilidade de aplicar a suspensão condicional da pena (sursis) e a transação penal.

A não aplicabilidade dos dois institutos despenalizadores está previsto no Artigo 41 da Lei no 11.340/2006 (LMP):

Art. 41. Aos crimes praticados com violência doméstica e familiar contra a mulher, independentemente da pena prevista, não se aplica a Lei no 9.099, de 26 de setembro de 1995.

Porém este dispositivo também gerou controvérsia, então o STJ no Enunciado 536 estabeleceu que "a suspensão condicional do processo e a transação penal não se aplicam na hipótese de delitos sujeitos ao rito da Lei Maria da Penha".

A constitucionalidade deste artigo chegou a ser questionada, pela razão de que a Lei Maria da Penha é uma lei ordinária que afasta a aplicação de outra lei ordinária. No julgamento da ADC 19, o STF entendeu o artigo como constitucional:

O Tribunal, por unanimidade e nos termos do voto do Relator, julgou procedente a ação declaratória para declarar a constitucionalidade dos artigos $1^{\circ}, 33$ e 41 da Lei $n^{\circ} 11.340 / 2006$ (Lei Maria da Penha). Votou o Presidente, Ministro Cezar Peluso. Falaram, pelo Ministério Público Federal (ADI 4424), o Dr. Roberto Monteiro Gurgel Santos, Procurador-Geral da República; pela Advocacia-Geral da União, a Dra. Grace Maria Fernandes Mendonça, Secretária-Geral de Contencioso; pelo interessado (ADC 19), Conselho Federal da Ordem dos Advogados do Brasil, o Dr. Ophir Cavalcante Júnior e, pelo interessado (ADI 4424), Congresso Nacional, o Dr. Alberto Cascais, Advogado-Geral do Senado. Plenário, 09.02.2012.

Um avanço jurisprudencial que a Lei Maria da Penha conquistou foi a não aplicação do princípio da insignificância nos casos de violência 
doméstica e familiar. No HC 369.673, o STJ decidiu não ser aplicável o princípio. Segundo o Ministro Relator Rogerio Schietti Cruz, a lei ofereceu:

\begin{abstract}
"concretude ao texto constitucional e aos tratados e convenções internacionais de erradicação de todas as formas de violência contra a mulher, com a finalidade de mitigar, tanto quanto possível, esse tipo de violência doméstica e familiar (não só a violência física, mas também a psicológica, a sexual, a patrimonial, a social e a moral)".
\end{abstract}

Com a LMP o Código Penal sofreu alterações em relação à violência contra a mulher, foram adicionados os seguintes pontos:

Art. 61 - São circunstâncias que sempre agravam a pena, quando não constituem ou qualificam o crime:(Redação dada pela Lei $\mathrm{n}^{\circ}$ 7.209, de 11.7.1984)

f) com abuso de autoridade ou prevalecendo-se de relações domésticas, de coabitação ou de hospitalidade, ou com violência contra a mulher na forma da lei específica; (Redação dada pela Lei $\mathrm{n}^{\mathrm{o}} 11.340$, de 2006)

E também o seguinte artigo foi modificado:

Art. $129 \S 9^{\circ}$ Se a lesão for praticada contra ascendente, descendente, irmão, cônjuge ou companheiro, ou com quem conviva ou tenha convivido, ou, ainda, prevalecendo-se o agente das relações domésticas, de coabitação ou de hospitalidade: (Redação dada pela Lei n ${ }^{\circ} 11.340$, de 2006)

A lei desde sua criação até hoje vem sofrendo críticas, por parte dos juristas e até mesmo do movimento feminista. Neste ponto irá ser exposto algumas dessas críticas e problemáticas, e algumas delas rebatidas.

A primeira questão a ser exposta é a questão da constitucionalidade da Lei Maria da Penha, alguns -juristas- defendem que a lei é inconstitucional, pois fere o artigo da Constituição Federal que versa sobre a igualdade entre homens e mulheres ${ }^{14}$.

Essa questão precisa de ser rebatida, pois para proporcionar a igualdade perante os iguais são tratados igualmente e os desiguais, estes têm que ser tratados desigualmente. (NERY JUNIOR, 1999, p. 42).

\footnotetext{
${ }^{14}$ Artigo 5º, inciso I da Constituição Federal de 1988 dispõe: "homens e mulheres são iguais em direitos e obrigações, nos termos desta Constituição".
} 
Não faltam justificativas para tratar, nesta questão de violência doméstica e familiar, as mulheres de forma diferenciadas, dentre elas está à ideologia patriarcal da sociedade e do sistema penal-jurídico brasileiro, que se mostrava omisso em relação a isso -chegando inclusive a ser condenado internacionalmente, como já mencionado acima-, e que durante anos mostrou uma postura discriminatória quanto às mulheres. Pode-se concluir então que a Lei é constitucional, uma vez que visa suprir e promover a igualdade de fato e cumprir o princípio da igualdade imposto pela Constituição Federal.

Um ponto a ser criticado são as DDMs (Delegacia da Mulher), esse instituto foi implementado pela primeira vez em São Paulo no ano de 1985 e abarcada pela LMP:

Sua origem e proposta são de grande avanço no mundo jurídico e social para tratar da problemática que é a violência doméstica e familiar, porém na realidade não é efetivo como deveria ser. A Delegacia da Mulher ainda requer uma especialização e capacitação no que dizem respeito aos seus funcionários, estes precisam compreender o ciclo da violência que a mulher sofre, os processos de vitimização e toda a questão da ideologia patriarcal da sociedade, as problemáticas sobre gênero. Os policiais que atendem nessa Delegacia especializada recebem treinamento na Academia de Polícia, ou seja, o comum que é oferecido para o combate ao crime, mas não é disponibilizado um específico para atender em uma DDM.

A mulher ao ir até delegacia denunciar seu companheiro, ou parente, já passou por todo um processo de vitimização e ao chegar e se deparar com ajuda não preparada especificadamente para esse tipo de violência, acaba sofrendo uma revitimização, pois apesar de ser uma delegacia especializada, apresenta essa falta de especialização e preparo para lidar com esse tipo de realidade, e assim podem, mesmo que inconscientemente, estar agindo com discriminação e por consequência, a vítima se sente envergonhada e incapaz para estar ali, desistindo assim da denúncia e voltando para o ciclo da violência, podendo resultar em um caso mais grave de violência doméstica, o ápice, que é o Feminicídio ${ }^{15}$.

\section{$7 \quad$ CONCLUSÃO}

\footnotetext{
${ }^{15}$ Lei no 13.104 de 9 de Março de 2015.
} 
Com a pesquisa acima desenvolvida, estudada e analisada, os resultados encontrados foram os que a seguir irei explicitar, além das constatações assertivas que se concluiu ao longo do desenvolvimento da pesquisa.

A LMP surgiu diante de uma deficiência dos Poderes Legislativo e Judiciário para lidar com delitos que envolvem questões de gênero. Foi concebida para proteger a mulher em situação de vulnerabilidade em uma relação doméstica, familiar ou íntima.

Como resultado da Lei, afastou-se a competência dos JECRIMs para casos de violência contra a mulher; e, com isso, as medidas despenalizadoras.

A Lei, por si só, não garante que o agressor deixará de praticar a violência. Além disso, em grande parte dos casos, a representação da vítima envolve diversas hesitações, seja por medo ou por outras razões sociais.

Conclui-se que a vitimização de gênero decorre de estruturas sociais patriarcais. A LMP, por si, é ineficaz na prevenção da violência contra a mulher, e suas disposições penais não são suficientes para mudar a visão patriarcal de sociedade. Para o aprimoramento dos mecanismos de proteção dos direitos da mulher, sejam eles penais ou extrapenais, é essencial uma compreensão sistemática das contingências sociais que envolvem as vitimizações relacionadas a gênero.

Para garantir que a LMP tenha efetividade, é necessário uma mudança, primeiramente, no âmbito social. No âmbito jurídico, e da lei mais especificadamente, precisa-se que seja colocado em prática real o que a lei prevê, como a iniciativa de políticas públicas para a prevenção da violência doméstica e familiar, a delegacia da mulher, para melhorar sua cooperação com a luta contra a violência, necessita de capacitação especializada de seus funcionários, para que saibam agir de forma com que a vítima não se sinta oprimida. A lei prevê os Juizados Especiais, porém como facultativo, portanto, o número reduzido destes não oferece à lei um efetivo cumprimento.

A Lei Maria da Penha possui grande representividade e importância no mundo jurídico, promoveu um alcance maior para a igualdade, suprindo a dívida que o Estado possuía com as mulheres, depois de anos de tratamentos desiguais, em que o homem era visto como detentor de todo o poder, e a mulher como incapaz, submissa a ele.

A lei precisa ir além do caráter punitivo, pois o intuito de sua existência não é a criação de mais atos delituosos, é necessário que haja 
políticas públicas de prevenção e de conscientização para que as futuras gerações já cresçam com a visão de uma sociedade mais igualitária entre homens e mulheres e não como ainda é hoje, uma sociedade pautada na ideiologia patriarcal.

\section{REFERÊNCIAS BIBLIOGRÁFICAS}

ALVES, Branca Moreira; PITANGUY, Jacqueline. O que é FEMINISMO. São Paulo: Abril Brasiliense, 1985.

AZEVEDO, Rodrigo Ghiringhelli de (Org.). Relações de Gênero e Sistema Penal: violência e conlitualidade nos juizados de violência doméstica e familiar contra a mulher. Porto Alegre:

Edipucrs, 2011. 200 p.

BARROS, Flaviane de Magalhães. A Participação da Vítima no Processo Penal. Rio de Janeiro: Lumen Juris, 2008.

BIANCHINI, Alice. O que é "violência baseada no gênero"?: Art. 5 da Lei Maria da Penha. 2015. Disponível em: <https://professoraalice.jusbrasil.com.br/artigos/312151601/o-que-e-violenciabaseada-no-genero>. Acesso em: 06 jun. 2018.

BONNETI, Alinne. SOUZA, Ângela Maria Freire de Lima e. (org.).Gênero, mulheres e feminismo. Salvador : EDUFBA : NEIM, 2011.346 p. - (Coleção Bahianas ; 14)

BRASIL. Lei 11.340, de 07 de agosto de 2006. Dispõe sobre a violência doméstica e familiar contra a mulher. Disponível em: 〈http://www.planalto. gov.br>. Acesso em:

BRASIL. Lei $\mathrm{N}^{\circ} 11.340$, 2006. Lei Maria da Penha. Disponível em: <http://www.planalto.gov.br/ccivil_03/_ato2004-2006/2006/lei/111340.htm> . Data de acesso: 20 de set. de 2015.

BUENO, Mariana Guimarães Rocha da Cunha. Feminismo e Direito Penal. 2011. 180 f. Dissertação (Mestrado) - Curso de Direito, Faculdade de Direito da Universidade de SÃo Paulo São Paulo, São Paulo, 2011.

BUTLER, Judith P. Problemas de gênero: feminismo e subversão de identidade/ tradução, Renato Aguiar - Rio de Janeiro: Civilização Brasileira, 2003.

CAMPOS, Carmem Hein de. Desafios na Implementação da Lei Maria da Penha. Revista Direito Gv, São Paulo, v. 2, n. 11, p.391-406, jul. 2015.

CAMPOS, Carmen Hein de (Org.). Lei Maria da Penha comentada em uma perspectiva jurídicofeminista. Rio de Janeiro: Editora Lumen Juris, 2011. 375 p. 
CARVALHO, Sandro Carvalho Lobato de; LOBATO, Joaquim Henrique de Carvalho. Vitimização e processo penal. Revista Jus Navigandi, ISSN 1518-4862, Teresina, ano 13, n. 1937, 20 out. 2008. Disponível em: <https://jus.com.br/artigos/11854>. Acesso em: 19 abr. 2018.

CONVENÇÃO INTERAMERICANA PARA PREVENIR, PUNIR E ERRADICAR A VIOLÊNCIA CONTRA A MULHER. Disponível em: 〈http://www.dhnet.org.br/direitos/sip/oea/mulher2.htm〉 Acesso em: 12 jan. 2018

COUTO, Maria Cláudia Girotto do. Lei Maria da Penha e princípio da subsidiariedade: diálogo entre um direito penal mínimo e as demandas de proteção contra a violência de gênero no Brasil./Maria Cláudia Girotto do Couto. São Paulo: IBCCRIM, 2017.

DIAS, Maria Berenice. A Lei Maria da Penha na justiça. 2. Ed. São Paulo: Revista dos Tribunais, 2010.

DIAS, Maria Berenice. A Lei Maria da Penha na Justiça: a efe tividade da Lei 11.340/2006 de combate à violência doméstica e familiar contra a mulher. São Paulo: Revista dos Tribunais, 2007.

DORLIN, Elsa. Séxo, género y sexualidades. Introdución a la teoria feminista $-1^{\circ}$ ed. - Buenos Aires: Nueva Visión, 2009. 128 p.

FACIO, Alda; FRIES, Lorena. Género y Derecho. Santiago de Chile: La Morada, 1999. 534 p.

FATTAH, Ezzat A.. From Crime Policy to Victim Policy: Reorienting the justice system. United States of America: The Macmillan Press Ltd, 1986.

FATTAH, Ezzat A.. Towards a Critical Victimology. United States of America: The Macmillan Press Ltd, 1992.

FERNANDEZ, Marilyn. Restorative justice for domestic violence victims : an integrated approach to their hunger for healing. United Kingdom: Lexington Books. 2010.

FLAVIN, J. (2004). Feminism for the mainstream criminologist: An invitation. In P. J. Schram \& B. Koons-Witt (Eds.), Gendered (in)justice: Theory and practice in feminist criminology (pp. 68-92). Long Grove, IL: Waveland Press

HERMANN, LEDA MARIA. Maria da Penha Lei com nome de mulher: considerações à lei 11334/2006: contra a violência doméstica e familiar, incluindo comentários artigo por artigo. Campinas, Servanda Editora, 2008

LARRAURI, Elena. Mujeres, derecho penal y criminologia. Madrid, Siglo Veintiuno Editores.1994.

Mapa da Violência 2015: homicídios de mulheres no Brasil. Disponível em:

http://www.mapadaviolencia.org.br/pdf2015/MapaViolencia_2015_mulheres.pdf.

MISTRETTA, Daniele. Lei Maria da Penha: Por que ela ainda não é suficiente? Revista do Laboratório de Estudos da Violência da Unesp/marília, Marília, v. 8, n. 1, p.1-8, dez. 2011. 
MOROTTI, Carlos. Vitimização primária, secundária e terciária. 2015. Disponível em <https://morotti.jusbrasil.com.br/artigos/210224182/vitimizacao-primaria-secundaria-e-terciaria> Acesso em: 25 de maio de 2018.

MORRISON, W. Compreender a filosofia do direito feminista. In: Filosofia do Direito: dos gregos ao pós modernismo. 2. Ed. São Paulo: WMF Martins Fontes, 2012.

NOVO, Wellington Carlos dos Santos. A Lei Maria da Penha e as medidas de proteção à mulher. Conteudo Juridico, Brasilia-DF: 10 jun. 2016. Disponivel em:

<http://www.conteudojuridico.com.br/?artigos\&ver=2.56058\&seo=1 >. Acesso em: 06 fev. 2018.

OLIVEIRA, Frederico Abrahão de. Vítimas e Criminosos, Porto Alegre: Livraria do Advogado, 1993.

PINTO, C. R. J. Uma história do feminismo no Brasil. São Paulo: Fundação Perseu Abramo, 2003.

ROVINSKI, Sônia Liane Reichert. Dano psíquico em mulheres vítimas de violência. Rio de Janeiro: Lumen Juris, 2004.

SAFFIOTI, Heleieth I.B.Contribuições feministas para o estudo da violência de gênero.Cadernos Pagu,n.16, p. 115-136, 2001.

SAFFIOTI, Heleieth; ALMEIDA, S.A. Violência de Gênero.Rio de Janeiro: Revinter, 1995.

SAFFIOTI, Heleieth. Gênero, patriarcado, violência. São Paulo: Editora Fundação Perseu Abramo, 2004.

SEVERI, Fabiana Cristina. Enfrentamento à violência contra as mulheres e à domesticação da Lei Maria da Penha: elementos do projeto jurídico feminista no Brasil. Ribeirão Preto - SP, 2017.240p.

TELES, Maria A. de Almeida. MELO, Mônica. O que é violência contra a mulher. São Paulo: Brasiliense, 2002.

TELES, Maria Amelia de Almeida. Breve História do Feminismo no Brasil. São Paulo: Brasiliense, 1999. 